\title{
THE ORTHOPAEDIC ASPECTS OF ONE HUNDRED CASES OF SPINA BIFIDA
}

By T. L. Carr, F.R.C.S., Aberdeen, Scotland.

From the Institute of Orthopaedics and the Royal National Orthopaedic Hospital, London

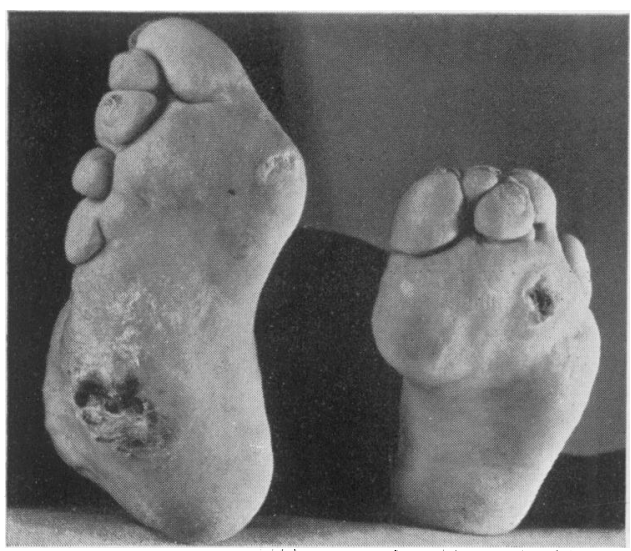

FIG. I

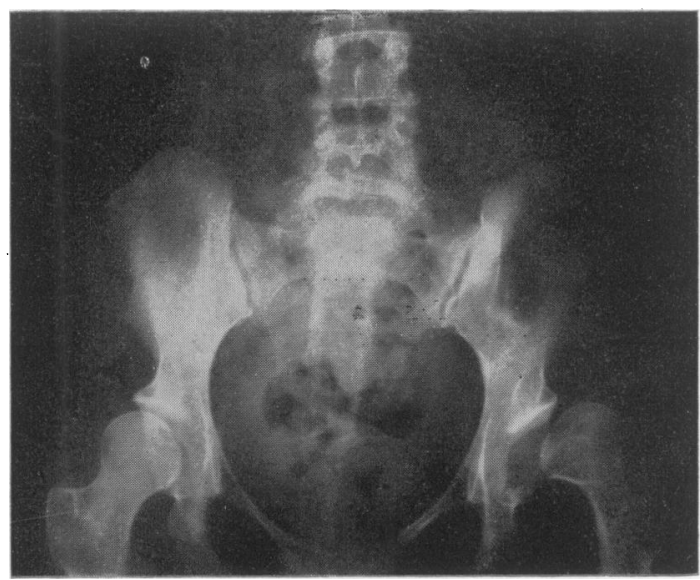

FIG. 2

TABLE I

Associated Anomalies in One Hundred Patients

I. Lumbo-sacral anomalies such as vertebrae of transitional type and vertebrae with abnormally shaped bodies, spinous processes and neural arches

2. Scoliosis ( 18 congenital, 2 idiopathic)

3. Congenital fusion of vertebrae, involving from 2-12 segments

4. Congenital lumbo-sacral spondylolisthesis

5. Hypoplasia of sacrum

6. Abnormal ribs (fusion, absence or deformity)

7. Syndactyly of fingers

8. Sacro-coccygeal dermoid

9. Café-au-lait type of pigmentation of trunk and limbs

10. Osteochondritis juvenilis (hip 3, spine 3)

I1. Congenital absence of pectoralis major 2, thyroglossal cysts 3 , congenital absence of vagina $I$, imperforate anus 2 , and macromastia I

$$
\text { Total } \frac{9}{110}
$$

matosis, but no case resembling those described by him was encountered.

\section{The Spinal Lesion}

For the purpose of describing the spinal lesion the patients have been divided into two groups:- -

(I) Twenty-three patients with myelocele or s $\therefore$ meningoole. 
(2) Seventy-seven patients with spina bifida occulta.

\section{GROUP I: Myelocele and Meningocele}

All but two of the twenty-three patients had extensive involvement of the nervous system. Most of them had had operations on the myelocele or meningocele within a few months of birth but there was no definite evidence of neurological improvement in any case. The neural arch defect usually involved five or more segments and in one patient no less than twelve arches were defective. Both laminae were often completely absent, and the site of the lesion was most frequently lumbo-sacral. When the defect was small it was nearly always centrally placed (Tables 2 to 5 ).

Analysis of the Defects in Twenty-three cases of Myelocele and Meningocele

TABLE 2

Number of vertebrae involved Number of patients

$\begin{array}{rr}1 & 2 \\ 2 & 3 \\ 4 & 2 \\ 5 & 4 \\ 6 & 4 \\ 7 & 2 \\ 9 & 2 \\ 12 & 3 \\ & 2\end{array}$

TABLE 3

Size of neural arch defect Number of vertebrae involved

I. Less than $\mathrm{I} \mathrm{cm}$. in

width on the radio-

graph

2. Subtotal

3. Total

81

\begin{tabular}{lr}
\multicolumn{2}{c}{ TABLE 4} \\
Site of lesion & Number of patients \\
Cervical & I \\
Thoraco-lumbo-sacral & 2 \\
Lumbar & 4 \\
Lumbo-sacral & I5 \\
Sacral & I
\end{tabular}

TABLE 5

Site of small neural arch defects
I. Central
2. Right laminar
3. Left laminar

Number of vertebrae involved

\section{GROUP II: Spina Bifida Occulta}

In this group half of the patients showed involvement of only one or two vertebrae while the remainder showed defects as extensive as those found in myelocele and meningocele. When only one segment was involved it was the first sacral in seventy-five per cent. of cases. The laminar defects were smaller in a higher proportion of the patients than in Group I, but in the extensive lesions the laminae were usually completely absent, just as in the myelocele group. The commonest site of the lesion was again lumbo-sacral and the smallî. defects were usually placed centrally (see Tables 6 to 9$)$.

Analysis of the Defects in Seventy-seven cases of Spifia Bifida Occulta

TABLE 6

Number of vertebrae involved Number of patients

\begin{tabular}{|c|c|}
\hline $\begin{array}{l}\text { ertebrae involved } \\
\text { I }\end{array}$ & $\begin{array}{c}\text { Number of patients } \\
28\end{array}$ \\
\hline 2 & I I \\
\hline 3 & 7 \\
\hline 4 & 4 \\
\hline 5 & 9 \\
\hline 6 & 7 \\
\hline $\begin{array}{l}7 \\
8\end{array}$ & $\begin{array}{l}5 \\
3\end{array}$ \\
\hline 9 & 2 \\
\hline I I & I \\
\hline
\end{tabular}

*This was the first sacral segment in 21 of the patients.

TABLE 7

Size of neural arch defect Number of vertebrae involved

I. Less than $\mathbf{r} \mathbf{~ c m}$. in width on the radio-

graph

2. Subtotal

3. Total

I4I

113

TABLE 8

Cervical Site of lesion

Cervico-thoracic and sacral

Cervical and lumbo-sacral

Thoracic

Thoraco-lumbar

Thoraco-lumbo-sacral

Lumbar

Lumbo-sacral

Sacral

Number of patients

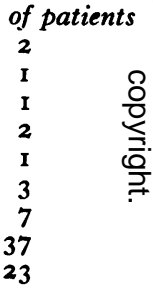

TABLE 9

Site of
small neural arch defects
I. Central
2. Right laminar
3. Left laminar

Number of vertebrae involve

Cutaneous and subcutaneous changes wete present in just over fifty per cent. of the patients with spina bifida occulta (Table ro); in the remainder the skin and subcutaneous tissues of the back were normal, although in five there was 9 bony gap large enough to be easily palpable.

\section{TABLE IO}

Cutaneous and subcutaneous evidence of spina bifida occulta in 39 patients

Hairy patch

Haemangioma and telangiectasis

Palpable bony defect

Scarring

Lipoma

Lumbar linear scleroderma

Dimples

Pigmentation of skin

Of the seventy-seven patients in Group i I fift had neurological lesions. The presence either of 
cutaneous and subcutaneous changes or of extensive laminar defects indicated that involvement of the nervous system was likely, although they were occasionally present when the central nervous system was normal. Of those cases without superficial evidence of spina bifida fifty per cent. had neurological lesions (Tables II and 12).

\section{TABle I I}

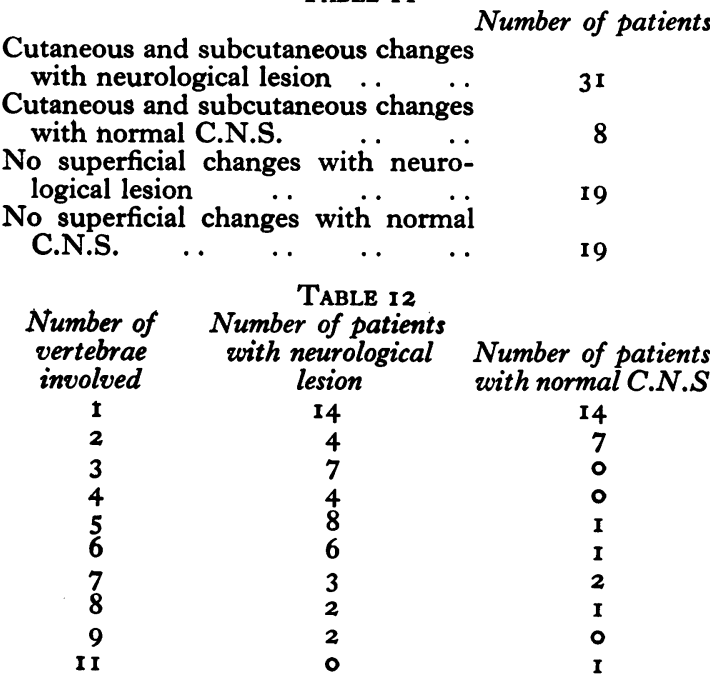

Tables 6 and 12 indicate that about fifty per cent. of the patients with spina bifida occulta of the first sacral segment had neurological lesions. This high figure is of course the result of the selection of patients to which I have already referred. By contrast Campbell Golding (1950) has found spina bifida occulta of the first sacral segment in nineteen per cent. of adult patients subjected to routine radiological examination.

\section{Neurological Lesions}

Neurological examination of all the hundred patients showed the following features:-

I. Nervous involvement was usually more severe and more extensive in the myelocele and meningocele group but equally severe disturbances were found occasionally in spina bifida occulta.

2. The lower lumbar and sacral segments of the cord were most frequently involved.

3. Sensory and motor paralysis usually occurred together but either could be present alone.

4. Both the sensory and the motor paralysis were usually bilateral. In the unilateral cases the numbers of right and left lower limbs affected were equal.

5. Motor paralysis was usually of the lower motor neurone type but in thirty per cent. of the patients signs of pyramidal tract involvement were present. In most patients the paralysis was incomplete; certain muscles tended to escape and various patterns of paralysis thus emerged.

\section{Paralysis Affecting the Hip}

Twenty-one patients had paralysis of muscles controlling the hip. In five it was unilateral, slight and accompanied by a similar degree of paresis in the rest of the limb. In sixteen the paralysis was severe, bilateral and accompanied by extensive paralysis more distally.

Three main groups were observed:-

I. Paralysis affecting all muscles uniformly but varying in severity from case to case.

2. Paralysis in which certain muscles were strong and others weak.

3. Paralysis associated with dysplastic changes in the hip (Table 13).

Table I3

Condition of the hip in 21 patients

Normal

Uniform hip paralysis

Paralysis with muscle imbalance

Paralysis with dysplastic changes

Number of hips

$$
\begin{array}{r}
5 \\
14 \\
12 \\
10 \\
\hline 41
\end{array}
$$

(One patient had a disarticulation through the hip at the age of fourteen years for a flail limb)

The first group showed three main clinical pictures:-

(a) Slight general weakness, all muscles being graded about 4 on the M.R.C. scale. These patients either had no complaints or felt that the affected hip was somewhat weaker than the other.

(b) A moderate degree of paralysis causing a Trendelenberg type of limp from abductor weakness.

(c) Severe paralysis with the joint completely or almost completely flail. In none of five such hips was dislocation present.

In the second group paralysis was again variable in severity and the striking feature was the existence of muscle imbalance. In two patients the flexors were normal, the extensors weak and the other muscles fairly evenly balanced. Flexion deformity of the hip ranging from 50 to 60 degrees was present. In the remaining ten hips in this group the flexors and especially the adductors were stronger than their antagonists-a cause of spontaneous dislocation of the hip described by Watson-Jones (1926) and Hart (1928). In five of these hips the joint was dislocated (Fig. 3). In four of the other five the short rotator muscles were not severely paralysed, their grading being between 3 and 4 . This suggests that these muscles normally may play an important part in maintaining the head of the femur within the acetabulum.

In the third group dysplasia of the hip was present as well as paralysis, four presenting the 


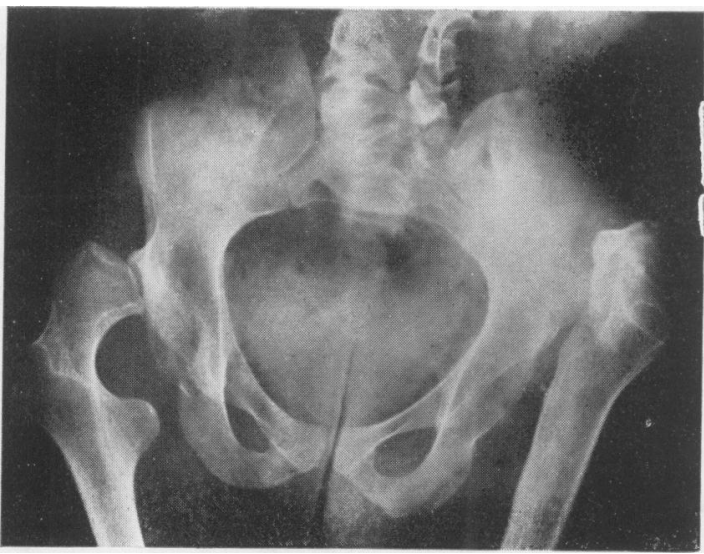

FIG. 3.-Bilateral paralytic dislocation of the hip.

typical appearance of congenital dislocation and six having a shallow socket with or without malformation of the acetabular rim.

The type of paralysis was again that of muscle imbalance of variable severity. Fig. 2 shows a subluxated hip with an inadequate socket in a patient with almost complete paralysis of the lower limbs. Fig. 4 shows the hips of a girl of six years who had a large myelocele and severe paralysis of the hip muscles. The flexors and adductors were just a little stronger than their antagonists and the acetabula were well forme Five years later (Fig. 5) the left hip was beging ning to subluxate and the acetabulum had become malformed: In five of the dysplastic hips dislo cation had occurred and subluxation was present in two.

Blundell Jones (-1954) has recently discussed the role of coxa valga in various types of paralytie dislocation of the hip. He found that an increas? of the angle between the neck of the femur and the shaft was invariable and that it was most severe when paralysis was present in the first two years of life. Piersol (1930) has stated that the normat angle ranges from 110 to 144 degrees in adults, the average being 125 degrees. At birth the angle of the neck may be I6o degrees, diminishing to if permanent angle by puberty. Blundell Jones (1954) found that the major part of the reduction. in the angle took place during the first five yeans of life:

I have been unable to confirm his finding tha coxa valga is " always present." In the thirty-sis hips of this series in which varying degrees of paralysis were present, fifteen showed definite coxa valga, the others being within the normat range. Of the twelve dislocated and subluxate hips six showed coxa valga, which was only severe in four instances. Paralysis had, of course, bgeff present in all these patients since birth.

Fig 6 shows the radiograph of the hip

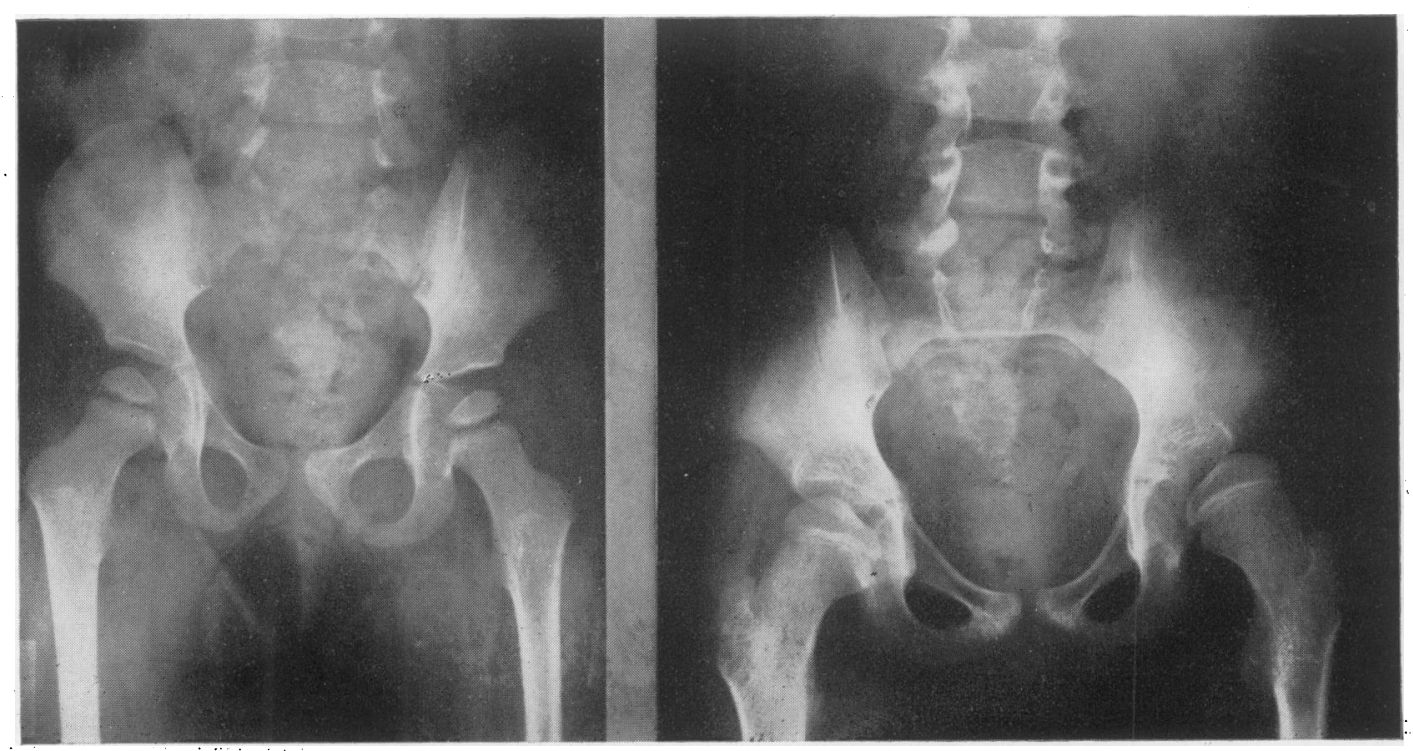

Fig. 4.-The radiograph at the age of six years of a child with an extensive lumbo-sacral spina bifida and severe paralysis of the lower limbs. The acetabula are well formed, but there is some degree of coxa valga.
FIG. 5.-The radiograph of the same child at the age of eleven years now shows a defective roof to the left acetabulum and early subluxation of the hip joint. 


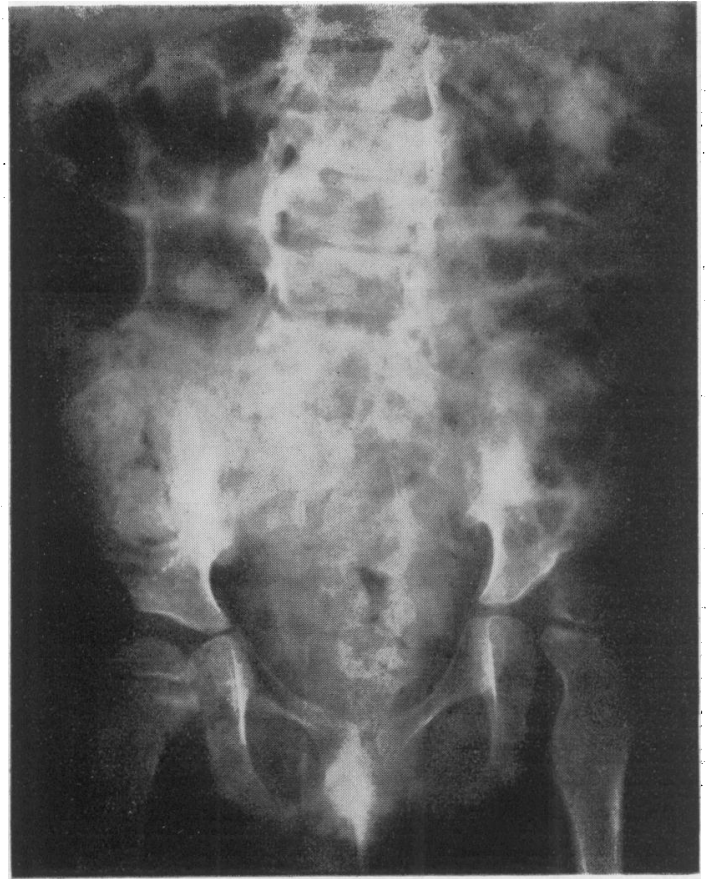

FIG. 6.-A radiograph of a child with extensive lumbosacral spina bifida and severe paralysis. There was considerable imbalance of the muscles controlling the left hip joint with complete paralysis of the short rotators. The left acetabulum is shallow and the coxa valga is severe. The hip has already dislocated.

boy with a large meningo-myelocele. This patient demonstrated all three of the factors which I believe tend to produce dislocation of the hip in these patients:-

(a) Severe paralysis; the flexors and adductors were stronger than their antagonists, whilst the short rotators were completely paralysed.

(b) A shallow acetabulum.

(c) Severe coxa valga.

\section{The Knee and the Leg}

Nineteen patients presented deformities of the knee joint; flexion deformity was by far the most frequent, and was bilateral in half of these patients. In the others the opposite knee was either recurved, flail or normal (Table I4).

\begin{tabular}{|c|c|c|c|c|c|}
\hline Condition of & the $k$ & ABLee & $\begin{array}{l}\mathrm{E} \text { I4 } \\
\text { joints in }\end{array}$ & 19 & patients \\
\hline xion de & ormity & . & $\cdots$ & $\cdots$ & 27 \\
\hline Back knee & $\ldots$ & $\cdots$ & . & $\cdots$ & 4 \\
\hline Flail & . & $\cdots$ & $\cdots$ & $\ldots$ & 4 \\
\hline Normal & $\cdots$ & $\cdots$ & $\cdots$ & $\cdots$ & 3 \\
\hline
\end{tabular}

The amount of flexion deformity varied from Io to 60 degrees, 30 degrees being frequent. In the majority the hamstrings and calf were strong

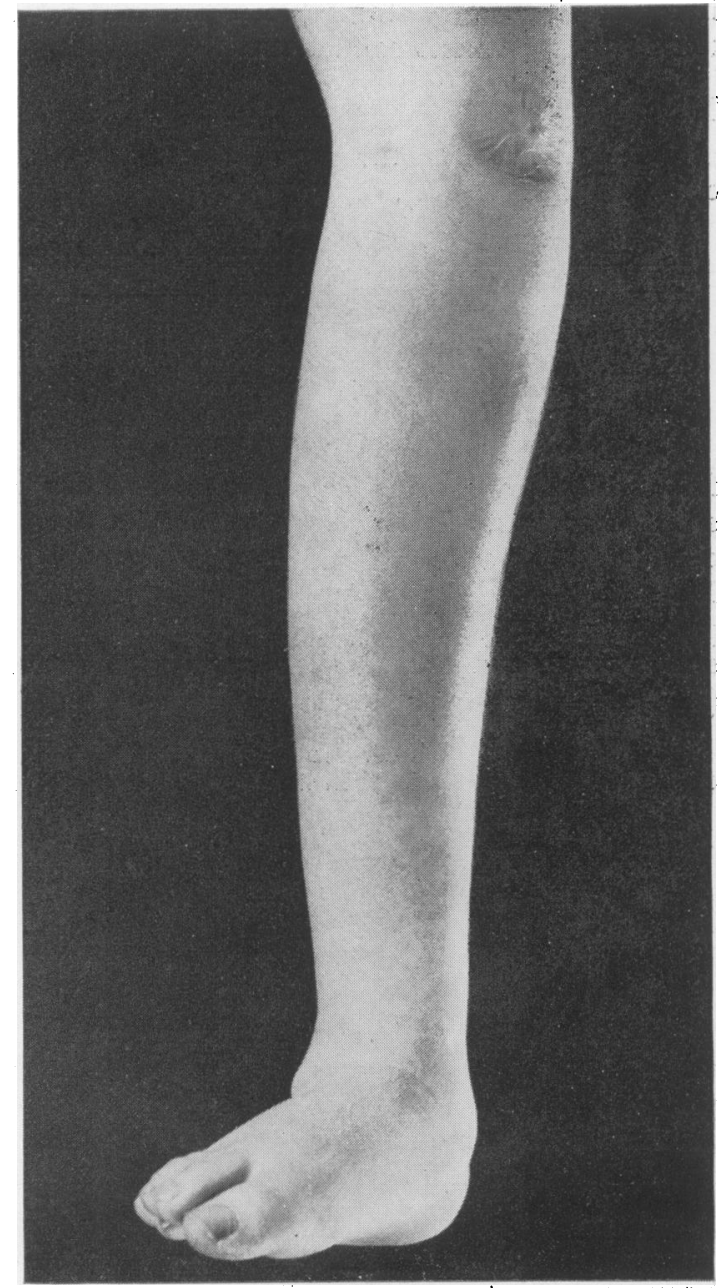

FIG. 7.-The right lower limb of a young gir! to show a marked external rotation deformity of the foot in relation to the femur (see text). Several years previously a gross equino-varus deformity had been corrected by radical tarsectomy. Next a fixed flexion deformity of the knee joint was corrected by complete tenotomy of the hamstrings. The scar just above the patella marks the site of a painless pressure sore from the post-operative plaster. The left leg was completely flail, and when a fracture of the femur occurred it was promptly amputated through the site of fracture.

and the quadriceps weak; occasionally the hamstrings were spastic. In a few the main cause of deformity was capsular contracture following years of nursing with the joint flexed. Only one of the four instances of back knee was severe. As might be expected, minor degrees of external rotation deformity of the lower limb were frequent in patients with flexion deformities of the hip and knee. Fig. 7 shows a severe deformity 
in a girl with a very strong biceps femoris and a tensor fasciae femoris contracture.

\section{The Foot}

Of all deformities, those of the feet were the commonest (Table I 5).

TABle I5

Bilateral symmetrical deformity .. 30

Bilateral asymmetrical deformity .. 6

$\begin{array}{llll}\text { Unilateral deformity } & \ldots & \ldots & 27\end{array}$

Total $\overline{\mathbf{6 3}}$

Equino-varus was much the commonest deformity and was frequently accompanied by secondary cavus. A few patients had a cavo-varus deformity only, some equinus being masked by the inversion of the hind foot. A smaller number presented with pes cavus alone; calcaneo-cavus, simple valgus and total paralysis were less common (Table 16).

TABLe 16

Condition of 126 feet in 63 patients

Equino-varus

Varus only

Cavus

Calcaneo-cavus

Valgus

Flail foot

Normal

Number of feet
48
9
23
6
3
10
27

Pes Equino-varus. The patients with equinovarus showed a wide range of the degree of paralysis. As a rule all muscle groups were involved to some extent, though the calf sometimes escaped completely. The posterior leg muscles were much stronger than those in the anterior compartment and the invertors always stronger than the peronei, which were usually severely paralysed. In most of the patients tibialis posticus was stronger than tibialis anticus. The deforming factors therefore are the strong calf, which itself tends to increase varus of the foot in the presence of equinus, the weak peronei and the relatively stronger tibial muscles. The most severe deformities occurred when the calf and tibialis posticus were powerful. Adduction of the forefoot was less severe than in congenital clubfoot and the heel seldom so poorly developed.

Many of the patients had been under treatment for some time when they were reviewed. Correction of the deformity by conservative measures such as strapping, splints and repeated plaster casts had frequently been regarded as successful, but cessation of treatment was often followed by rapid relapse according to the degree of muscle imbalance present. Transplantation of the tendon of the tibialis anticus to the outer side of the foot was performed in ten instances; in one foot there was over-correction, while all the others still showed equino-varus. In twenty instances Steindler operation had been performed and ng further treatment was contemplated unless des formity recurred. In a third of the patients wit equino-varus stabilisation of the foot by some type. of triple arthrodesis was eventually performed Half of these patients finally had feet of good shape and function and were able to wear ordinary shop shoes; in the other half some deformity remaines especially varus, due either to inadequate correction or to the continued action of deforming muscles.

A number of patients with mild equino-varus deformities had no treatment apart from inside irons with outside $\mathrm{T}$-straps, varus wedges to thas soles and heels and surgical boots. Nevertheless some deformity remained in most of the patien's who had attended hospital. The infrequency of the attempts to balance the foot by suitable tendom transplantation after closed or open correction the deformity suggested that the part played bis muscle imbalance had not been sufficient $\$$ recognised.

Pes Cavus. Pes cavus was much less frequent than equino-varus. The incidence of bilateri and unilateral deformity was equal. Half of these patients complained of pain under the metatarsal heads, of weakness of the foot and of inabilit $\$$ wear shop shoes. Most of those with pain 9 ad fixed hyperextension of the metatarso-phalangieg joints, rigid clawing of the toes and callositics under the metatarsal heads. The severity of the cavus was very variable and even in those with ñ symptoms and normal sensibility some very sevece deformities were observed. Electrical reactio $\vec{s}$ showed evidence of denervation in only fifty pôr cent.

Other deformities of the foot were uncommon. Only six patients had the calcaneo-cavus deformity so frequent in poliomyelitis, and three had a valgus deformity caused by weak peronei in otherwise flail feet. Complete flaccid paralysis below the knee was present in ten instances.

Impairment of Sensibility and its Sequelae윽

Fifty patients showed loss of sensibility. In the myelocele group sensory loss was severe and widespread; the lower lumbar and sactil dermatomes showed a similar frequency iof involvement and the higher lumbar segments were also sometimes affected. In patients with spina bifida occulta the fifth lumbar and first sacral dermatomes were affected far more fequently than any other.

The impairment usually involved every type $\stackrel{0}{-0}$ both exteroceptive and proprioceptive sensatiog. As a rule, pain, touch and thermosensibility we equally affected. Vibration sensibility was fe- 


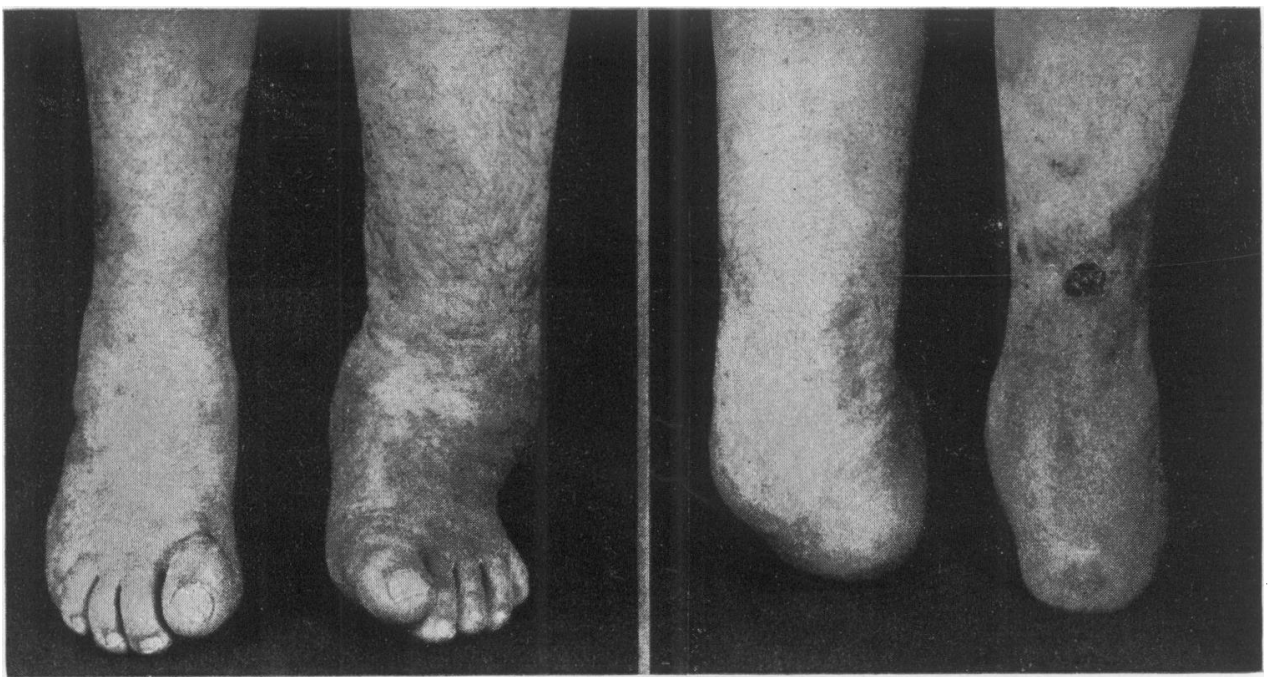

FIGS. 8 and 9.-The clinical and radiographic appearances of a patient with neuropathic arthritis of the left ankle and tarsal joints.

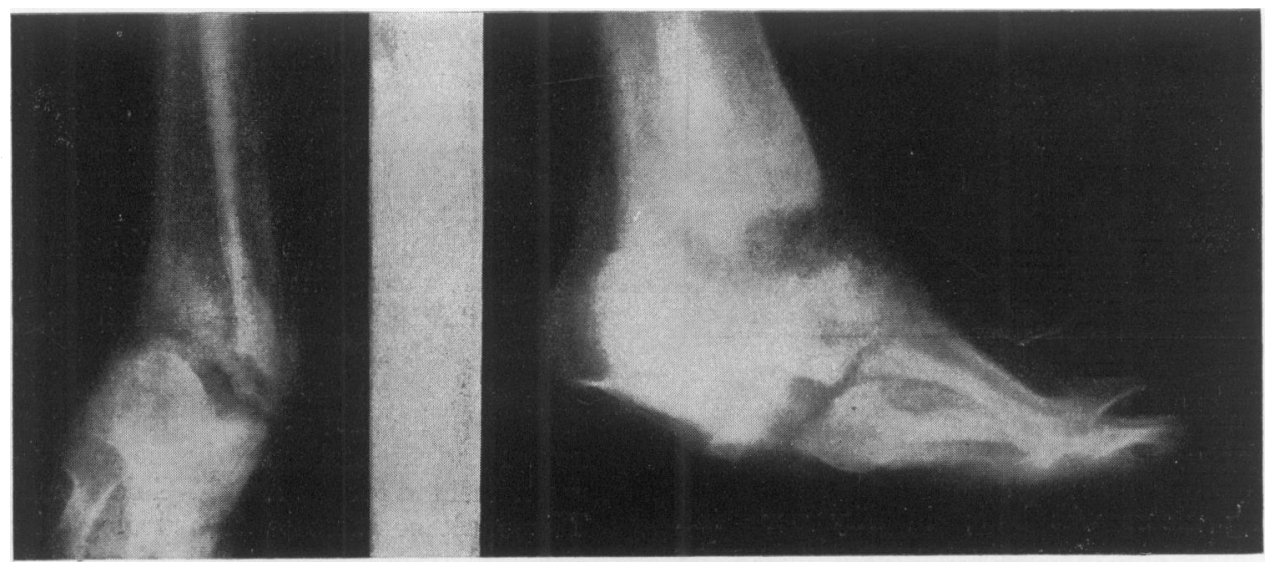

quently diminished and even lost if the exteroceptive loss were severe and widespread. Diminution of deep pressure and pain sensibility was frequent, but complete loss was rare. Loss of postural sensibility was uncommon, nearly always confined to the toes and feet, and accompanied by extensive motor paralysis and severe loss of other forms of sensibility. When the sensory disturbance was severe, trophic changes in the soft tissues, bones and joints were frequent. The skin was thin, often shiny, and either dry or hyperhidrotic. The nails were either brittle, ridged or short.

Ulceration. Trophic ulceration recurring over periods of years had been present in fifty per cent. of the patients with sensory loss. The common sites were the postero-lateral aspect of the heel, the outer side of the foot, the dorsum of the toes and the buttocks.

Perforating ulcers under the fourth or fifth metatarsal heads were present in six patients with equino-varus or cavo-varus deformities and severe sensory disturbances. They had all been present for years, healing slowly during periods of rest in bed and recurring on renewed activity. Complete correction of the deformity and the provision of suitable sponge rubber insoles was the only successful line of treatment, excision of the metatarsal heads and necks without correction of deformity being followed by early recurrence. Fig. I shows a patient with severe bilateral equino-varus deformity, a large trophic ulcer on the right foot and a perforating ulcer under the left fourth metatarsal head. The prognosis in 


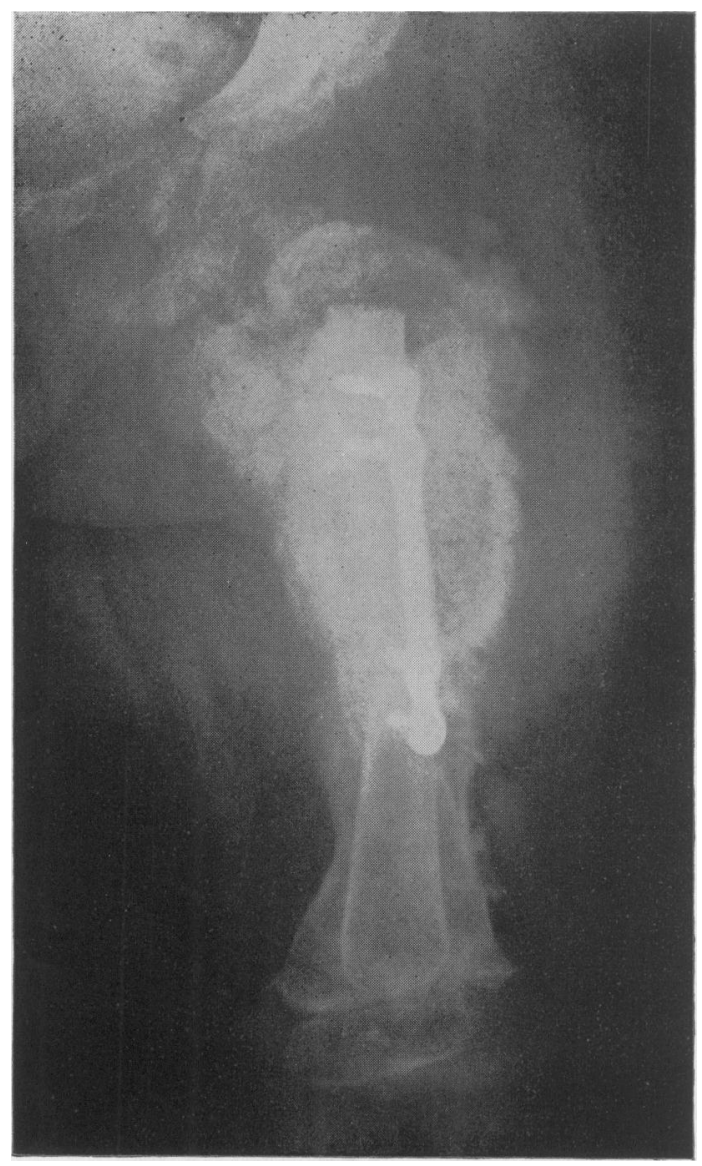

FIG. 10.- The radiograph of a boy aged four years to show excess callus formation after a spontaneous fracture of the upper end of the femur (see text)

perforating ulcers was bad; in fifty per cent. amputation became necessary because of increasing deformity, or of failure of attempts to correct it, or because of chronic sepsis.

Neuropathic Bones and Foints. Neuropathic arthritis of the ankle and tarsal joints developed in only one patient (Figs. 8 and 9). Spontaneous and almost painless fractures occurred in four patients. In two union took place normally; in the other two the fractures were notable for the development of excess callus. Fig. Io shows the radiograph of a boy of four who had a severely paralysed limb and a dysplastic hip. After the failure of conservative methods, open reduction of the hip and later a rotation osteotomy of the femur had been performed. After removal of the plaster he developed a supracondylar fracture while lying in bed and later a subtrochanteric fracture with a great mass of callus. Further fractures followed and the limb was eventually amputated. Histological examination showed normal callus and the "chondroid tissue described by Baker (1946) in the hyperplastie callus of osteogenesis imperfecta was not observe

Excessive callus in fractures associated with spina bifida has been reported by Gillies and: Hartung (1938) who described two instances of fracture of the upper tibia with sclerosis, frage mentation and excessive callus formation; thete was widening of the epiphyseal line and latera displacement of the head of the fibula. Therf cases bear a close resemblance to one case in thro series. A young girl with spina bifida, severel⿱亠 paralysed lower limbs and gross sensory impairment came to hospital complaining of swelling $\overrightarrow{\sigma f}$ the upper tibial region of the left leg. A radios graph showed the changes described by Gillies and Hartung but no fracture (Fig. I I). The Wasset: mann and Kahn reactions were negative. Onee year later the tibia had become almost normw again (Fig. 12). These changes are probably the result of trauma in a limb with decrease sensibility.

\section{Alterations in the Neurological Symptoms and Signs}

The neurological deficit in spina bifida has bee said to increase with growth, and Ingraham (I 943 has stated that this occurs frequently between ages of six and ten years. This is thought to be 6 fog - apart from the rare development of benign malignant neoplasms or of increased growth of lipomata already present-to tethering of the coris and cauda equina at the site of myelodysplasi電 with traction on the cord above resulting from difference in the rate of growth between the neural and skeletal axes, that is to say, the same mechanism as for the Arnold-Chiari malformation? The onset or increase of neurological change accepted by many as an indication for exploration. of the cord with a view to freeing the nervous tissue and thus preventing further deterioration. An increase in deformity is not necessarily due to further involvement of the nervous system and a perforating ulcer may be due only to increasing activity or weight bearing. I found definits evidence of an increase in the neurological deficit. such as the onset of urinary symptoms or the development of paralysis in a muscle previously known to be normal, in only five patients whose ages ranged from four to seventeen years.

\section{Summary}

I. One hundred patients with spina bifida havi been examined from the orthopaedic point of view and the associated anomalies enumeratedp

2. The spinal lesions in these patients are cons sidered in detail. 


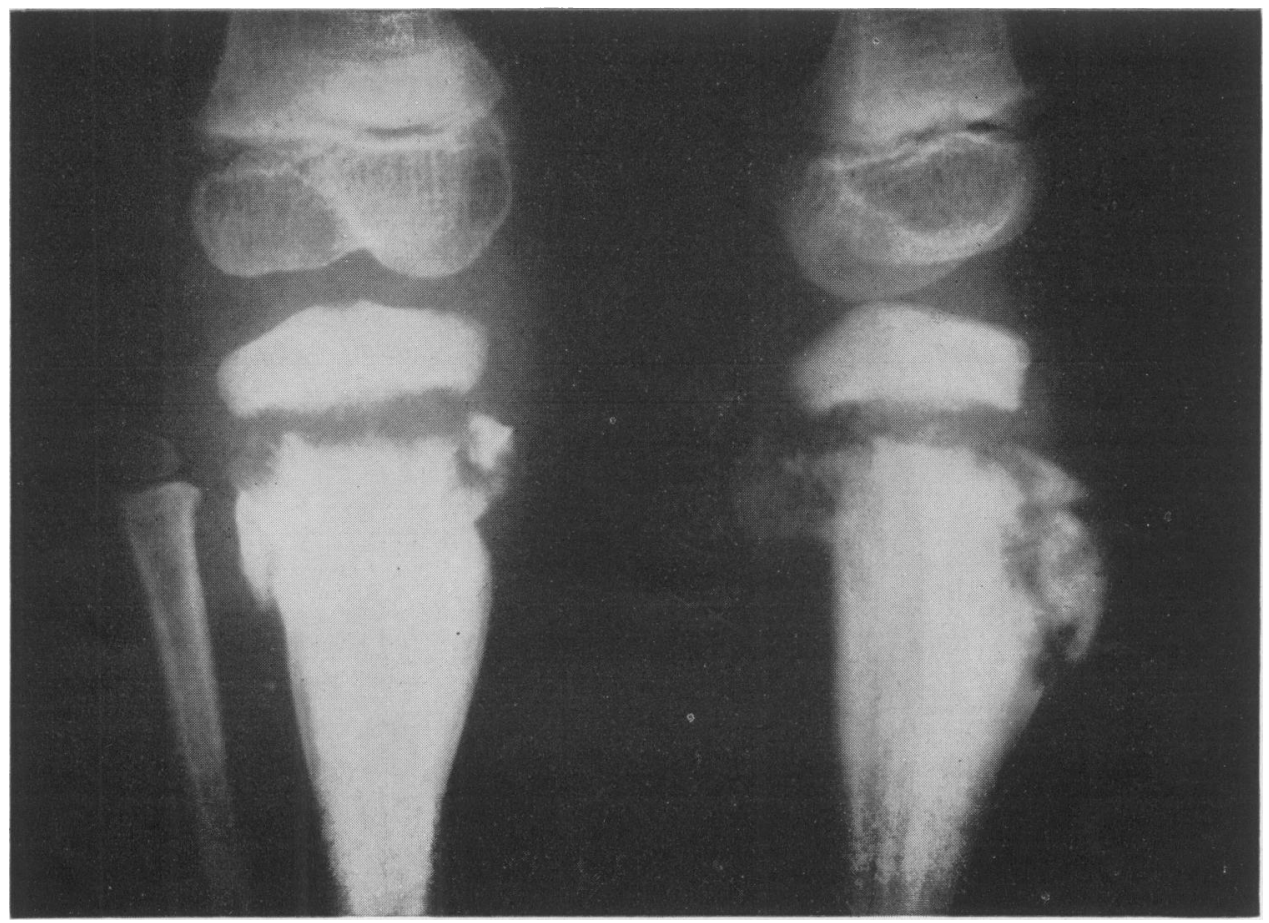

FIG. I I.-The radiographs of a young girl with spina bifida and gross sensory loss in both legs. A painless swelling of the upper tibia developed. Note the sclerosis of bone with appearances of fragmentation and new bone formation. The epiphyseal line is widened and the head of the fibula is displaced laterally.

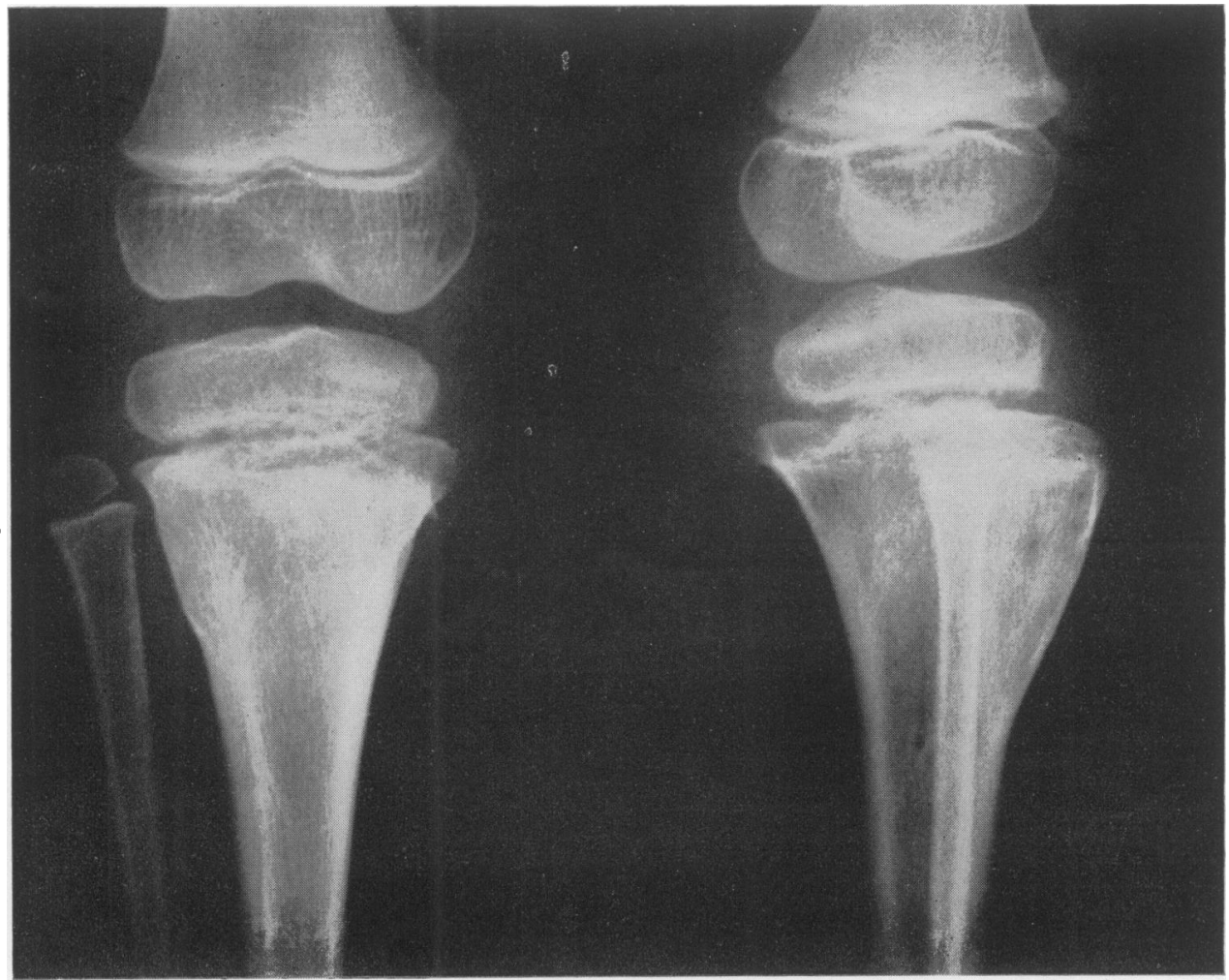

FIG. 12.-A radiograph of the same patient one year later showing spontaneous resolution of the changes. After a further year the films showed almost normal bone structure. 
3. A description of the motor paralysis in the lower limbs and its relation to various deformities is given.

4. The impairment of sensibility, its incidence and sequelae are described.

5. Progression of neurological changes is discussed.

\section{Postscript}

I wish to record my thanks to Mr. H. J. Seddon for arousing my interest in this subject and for his helpful criticism, to Mr. K. I. Nissen and Mr. J. I. P. James for their continuous encouragement and advice, and to all those members of the Consultant Staff of the Royal National Orthopaedic Hospital who kindly allowed me to examine their patients. I wish also to record my appreciation of the ever ready aid of the Medical Records Department of the Royal National Orthopaedic Hospital, the Department of Medical Photography and Librarian of the Institute of Orthopaedics.

\section{BIBLIOGRAPHY}

BAKER, S. L. (1946), 'Hyperplastic Callus Simulating Sarcom $\$$ two cases of Fragilitas Ossium,' Fournal of Pathology and Bacteriology, 58, 600.

GILLIES, C. L., and HARTUNG, W. (1938), 'Fracture of the Tibia in Spina Bifida Vera,' Radiology, 31,621 .

GOLDING, F. C. (195०), Discussion on the significance of ${ }^{\infty}$ genital abnormalities of the lumbo-sacral region, Proceedings Royal Society of Medicine, 43, 636.

HART, V. L. (1928), 'Spontaneous dislocation of the Hip Jint during early life: report of twenty-eight cases,' Archives of

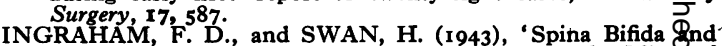
Cranium Bifidum: survey of 546 cases.' New England fournal of Medicine, 228, 559.

JONES, G. BLUNDELL (1954), 'Paralytic dislocation of the Hip,' Fournal of Bone and foint Surgery, 36-B, 375

KESSEL, A. W. LIPMANN (r95), "Intrathroacic meningoeele spinal deformity, and multiple neurofibromatosis,' Fournatiof Bone and Foint Surgery, 33-B, 87.

MACNAB, G. H. (I954), 'Spina Bifida Cystica,' Annals of the Rơval College of Surgeons of England, 14, 124.

PIERSOL G. A. (1930), Human Anatomy, ninth edition, 359 . WATSON-JONES, R. (1926), 'Spontaneous Dislocation of the Hilp,' British fournal of Surgery, 14, 36.

\section{OBSTETRICS \& GYNAECOLOGY}

(Postgraduate Medical Journal, July, 1954)

Price : 3s. 10d., post free

\section{INTRODUCTORY}

Charles D. Read, F.R.C.S., F.R.C.O.G.

RESPIRATORY HAZARDS IN THE PREMATURE INFANT

Albert E. Claireaux, M.D., M.R.C.P.

\section{POSTMATURITY}

S. G. Clayton, M.D., M.S., F.R.C.O.G.

THE RELATIVE MERITS OF THE VARIOUS BIOLOGICAL TESTS FOR PREGNANCY

H. P. Ferreira, M.D.

\section{PELVIC THROMBOSIS}

J. Stallworthy, F.R.C.S., F.R.C.O.G.

THE EARLY DIAGNOSIS OF GENITAL CANCER BY CYTOLOGY

Erica Waechtel, M.D.

THE MENOPAUSE

G. I. M. Swyer, D.M., M.R.C.P.

THE PLACE OF ULTRA-RADICAL SURGERY IN ADVANCED MALIGNANT DISEASE IN THE PELVIS

J. B. Blaikley, F.R.C.S., F.R.C.O.G.

Published by

THE FELLOWSHIP OF POSTGRADUATE MEDICINE

60, Portland Place, London, W.1

NOTICE OF SPECIAL INTEREST TO SUBSCRIBERS:

" WHY NOT HAVE YOUR COPIES OF THIS JOURNAL BOUND INTO YEARLY VOLUMES?"

Arrangements have now been made to have the twelve monchly issues fully bound in dark zreen pin head eloth, lettered in silt on spine with name of Journal, Volume Number and year, complete with index at front, 19s. 6d. per Volume, post free. A limited number of out of print journals are available to bind into volumes and make your library complete. Price on application siving decails of issues required to complete back volumes.

THE FELLOWSHIP OF POSTGRADUATE 60 PORTLAND PLACE, LONDON, W.I
MEDICINE 